\title{
Remembering Professional Commitments: Trusting in Teachers
}

\author{
JEANNIE BULMAN \\ Independent Consultant \\ CATHY BURNETT \\ Sheffield Hallam University \\ GUY MERCHANT \\ Sheffield Hallam University \\ EMMA ROGERS \\ Bishop Grosseteste University
}

\begin{abstract}
In England statutory expectations for literacy education place little emphasis on contemporary modes and media of communication and, as such, are out of step with contemporary life. We explore how open-ended, collaborative pedagogies can provide rich contexts for authentic everyday communication even in the context of such reductionist curriculum and assessment frameworks. This leads us to claim that the success of such approaches depends on the enthusiasm, experience and creativity of teachers and that remembering longstanding professional commitments in language and literacy teaching is at least as important as rethinking the curriculum when advocating for literacy provision more suited to current times.
\end{abstract}

\section{Introduction}

Currently, compulsory education in England is strongly shaped by state mandated curriculum and assessment and a pervasive culture of accountability, propped up by rhetoric about raising standards. On the surface of things, offering the very best to all students, regardless of their circumstances is uncontentious, being both aspirational and equitable. But turning to what is being valued, how standards are defined and measured, and what actually constitutes the very best is more troubling, and raises questions about whose needs are actually best served by the current arrangements. Such troubles are exacerbated by a reductivist model of evidence-based practice and a growing economy of commercial activity linked to professional learning and resource production that feeds off and works to sustain outdated conceptualisations of literacy. In curriculum guidance on English and literacy education the lack of emphasis given to current, everyday modes and media of communication is one of a number of concerns. In this respect education in England seems out of step with contemporary life.

In contrast scholarly activity in the field of literacy studies has made valiant attempts to keep pace with rapid technological change and unpredictable shifts in meaning 
making practices. Lively exchange and collaboration between those working in new literacies, multimodality, media studies and other related areas has given us tantalizing glimpses of emerging practices whilst pushing at the boundaries of methodological convention. Sometimes this work has influenced curriculum design, suggesting more contemporary educational provision in some jurisdictions, whilst at other times it has inspired and emboldened individual teachers to experiment and innovate in the classroom (e.g. Monkhouse et al., 2017). But in England, this work has had limited influence - the National Curriculum for English (which includes reading, writing and spoken language) contains no reference to digital media at all and, although concerns about the effects of social media and fake news have prompted an increased interest in criticality (National Literacy Trust, 2017), school improvement plans and professional learning events are far more likely to focus on the best way to promote children's literature or teach grammar than expanding notions of literacy. And where discussions do occur about the role of the digital, there is a prevailing feeling of uncertainty - are we about to abandon print literacy altogether? Are those kinds of writing that are composed with predictive text, a grammar checker, embedded sound and image, sprinkled with gifs and emojis on a handheld screen just a trivial passing fad? Or are they the shape of things to come? Is there still some value in what is often cursorily dismissed as traditional literacy? If literacy is now more complex and varied than ever before, how should we determine our classroom responsibilities and priorities?

Trying to negotiate this complex and expanding territory has sparked numerous attempts over the past two decades to generate more or less robust responses that might inform classroom practice. For example, the multiliteracies framework developed by Cope \& Kalantizis (2000) continues to be influential in curriculum design, whereas the work of Jenkins et al. (2009), with its identification of trends in new media use, is widely cited by advocates of new literacy. Importantly such responses recognize that integrating digital media within literacy education is not just something that needs to be done to prepare children for their future lives, but an important way of acknowledging and building upon what children are doing now (Kontovourki et al., 2019). However, implementing frameworks and guidelines that promote the integration of digital media can prove problematic not least because they do not always sit easily with existing school practices and priorities. Principles like those that two of us (Cathy and Guy) put forward in a Charter for 21st Century Literacies (Burnett, Davies, Merchant and Rowsell et al., 2014; Burnett and Merchant, 2018) therefore attempt to summarize thinking on contemporary literacy in ways that are sympathetic to classroom practice, blending what we know about contemporary communication practices with the everyday realities of teaching. In this paper we explore a collaborative primary school project that was informed by these principles, embedding new practices in everyday contexts. Reflecting on the energy and creativity of this work prompts us to suggest that remembering longstanding professional commitments and approaches in language and literacy teaching is at least as important as rethinking the curriculum when advocating for literacy provision more suited to current times. 


\section{1st Century Literacies}

Rather than embarking on proposals for a wholescale restructuring of curriculum or an approach that frames new literacies as a set of skills and competencies, through various publications the Charter for 21 st Century Literacies attempts to tease out principles or characteristics of new media practices that are both applicable to classrooms and generic enough to be adapted to local contexts (Burnett, Davies, Merchant and Rowsell, 2014; Burnett and Merchant, 2015; Burnett and Merchant, 2018). These principles constellate around the idea of classrooms as places for developing shared meanings and contexts for making a variety of texts. Although virtual learning has no shortage of advocates, and despite the fact that some of its potential has been unlocked with the school closures forced upon us by the Covid-19 pandemic, public education and its schools and classrooms are still a significant focus for sociality and community. They are a meeting place for adults, children and things - including the materials, resources and technologies that are to hand. The nine principles that we have been working with are intended to take the situatedness of education into account and give value to the everyday experiences of teachers and children. The principles are to:

\section{Acknowledge the changing nature of meaning making}

Resources for communication are now more numerous and varied than ever, and they are associated with new practices, conventions and habits of mind. As new communicative possibilities continue to emerge, it is time to revisit the scope and range of literacy in education.

2. Recognise and build on children's communicative, social and cultural repertoires

Children have diverse communicative, social and cultural repertoires, developed in their lives in and beyond school. Many children use a variety of digital devices, moving fluidly across different modes and media, combining digital and non-digital interaction, and/or use two or more languages and different registers within different kinds of interaction. At school, we need to provide contexts in which learners can draw from this developing repertoire in contexts that matter to them.

3. Acknowledge diverse modes and media While literacies have always been multimodal, we can capitalise on the opportunities generated by digital media for children to explore, develop and convey meanings in different ways.

4. Recognise the affective, embodied and material dimensions of meaning making

Literacies do not just happen on screen or paper, but are inflected by our feelings, our surroundings, and the people we are with. In providing for literacy in school we need to consider how people, places and things help shape the meanings children make.

5. Encourage improvisation and experimentation

Creative engagement is often unplanned and emergent. We should therefore facilitate opportunities for experimentation that recognise that meanings are made in the moment and do not always result in finished products.

\section{Use playful pedagogies}


Playful pedagogies have a role to play in cultivating risk-free environments in which children may follow interests, experiment and explore in ways that may take new or unexpected directions.

7. Create opportunities to work with the provisionality of digital media Digital texts are often provisional as they can be easily added to, re-worked and remixed. Building on such opportunities can allow children to reach new audiences, to be creative and/or critical in remixing what they or others have done, and to act on feedback.

\section{Provide contexts that facilitate criticality}

Schools can provide important contexts for children to critically consider their onand off-line practices, considering how they position themselves and are positioned by others. This may involve opportunities to re-work texts to reflect alternative experiences.

\section{Promote collaboration around and through texts in negotiating meaning}

Working on screen can provide rich and multiple opportunities for collaborationboth on and offline. We need to support children to take up such opportunities with confidence.

(Adapted and abridged from Burnett \& Merchant, 2018) In what follows we work with an example of practice drawn from a project in which the four of us explored how these principles might be taken up in the classroom. The $21^{\text {st }}$ Century Literacies Maker Circles Project was based on the simple proposition that teachers from two or more schools would work together to plan a project involving cross-school collaboration using an online space to provide meaningful and motivating opportunities for children to use digital media. Below we describe how the children in one group of four schools responded to this opportunity, before considering what their teachers brought to the planning process. The account of this work is assembled from the notes taken by Jeannie and artefacts she collected during the project.

\section{Project Background}

Jeannie worked with four primary teachers from different schools to develop a collaborative project based on an extended imaginative adventure which was inspired by recent news that NASA had plans to send an unmanned spacecraft to Mercury. Teachers met regularly in advance with Jeannie to prepare for the school-based work and agreed on the idea of sending astronauts to Mercury. The project took place over the course of the Autumn and Spring terms 2016-2017 and involved children between the ages of 9 and 11 who used Edmodo ${ }^{1}$ as a working platform. The children in each of the four schools were given different identities, with those in one school functioning as NASA, those in a second school as astronauts, in a third school as inhabitants of Earth, and in a fourth school as Mercury. The teachers wanted each group to work separately in order to establish their roles, and then gradually encounter each other as events unfolded. Collaborative work would be triggered by an email from NASA (in the first school), recruiting astronauts (from the second school) and sketching out the mission. The astronauts group would then develop particular characters and familiarise themselves with space travel. Meanwhile the Earth

\footnotetext{
${ }^{1}$ Edmodo is an online platform for use by schools that incorporates video
}

\begin{tabular}{lll}
\hline \hline Language and Literacy & Volume 23, Issue 2, 2021
\end{tabular}


group (from the third school) would be a forum for debate stimulated by a news report on the economic and ecological implications of space exploration. The inhabitants of Mercury (in the fourth school) would be unaware of everything that was happening elsewhere as they created their own civilisation - until they received a message to say that the astronauts were arriving. Once this idea had crystalized in the minds of the teachers they were able to build a scenario for the collaborative work. In what follows we describe some of what happened, focusing particularly on the contribution of the children in role as NASA and as the inhabitants of Mercury.

\section{Imagining Worlds}

The inhabitants of Mercury began creating their characters by considering their personalities, appearance and choosing names. During the first few sessions, they wrote about and drew these characters and finally made playdough models to use in future lessons. Through these quite traditional activities, the children developed a sense of community and pride in their imaginary planet. This investment was to prove important later on as it informed how they felt when they heard that the astronauts were landing. Using a combination of fact-finding and fiction they were then able to develop an idea of the environment on Mercury. They incorporated their characters into a story and created story maps to support oral storytelling. The children then worked together to create a class story involving all of the characters that they had invented. Once they had written their stories (see Figure 1 for an example) they created a stop motion animation using the playdough models that they had previously made. They also made a selection of props to include and created speech bubbles for the characters.

On the quiet planet of Mercury, there lived some aliens that were different shapes and sizes. They went to school 74 hours per day. On Monday November 7th 2016, they went on a school trip in their Hover Bus 3000 (by MF technologies) to see the meteorite shower at the crater. After four hours of travelling, the aliens parked their hover bus safely to have their lunch. The aliens that live on Mercury love Pringles and marmite sandwiches. .....

\section{Figure 1: An Extract from the Mercury Group's Writing}

Meanwhile on the other side of the county children working in the NASA group wrote an email to the astronauts containing the Mercury mission brief. The children then broke up into sub groups - a command and control group, a team of engineers and so on. Together they considered the problems those in space might face and discussed how these might be overcome. This generated a number of heated discussions about the likelihood of different problems and potential solutions. They also used a green screen to prepare a video link, publicising the mission to Mercury to the wider world and the astronauts. This process involved speech writing, and more formal language work. Having received details of their mission, the astronauts adopted various roles in teams, as pilots, mission commanders, specialists and so on. They created character descriptions, wrote an email to NASA to accept the mission, and then more messages to their families as they prepared to set off. 
Once in flight, they considered what they might see when they looked out of their shuttle window. Using a drawing app on the iPads, they created pictures of this new environment.

Back on Mercury, the children were informed that astronauts had been spotted approaching and discussed how they should respond. They had a poll to decide whether the astronauts should be allowed to land and be welcomed. Two thirds said 'no' as they were afraid of invasion, of being captured and taken to earth to be experimented upon! The others said that the astronauts should be welcomed - they could combine forces and benefit from the visitors' knowledge and experience of another planet. Before allowing the astronauts to visit Mercury they decided to send the astronauts some information about their planet. They drafted stories about their daily lives and created Morfo $^{2}$ videos which they emailed to the astronauts (see Figure 2).

Dear Astronauts,

Welcome to our amazing planet. Before you go and have a once in a life time opportunity on our awesome planet, I just want to say a couple of things: you don't need any food or water because the air that you breath in provides all the nutrients and liquids you need to survive.

On this planet there's a special school - it's only 72 hours a day, out of our 108 hour day! There are many animals on our marvellous planet, such as guinea pigs called Alien Petal and Alien Bramble. In our school you have a play time that is 10 hours long and a lunchtime that is 20 hours long. We have a fantastic time exploring our space-ground which has all the latest gadgets, hover boards and space

balls.

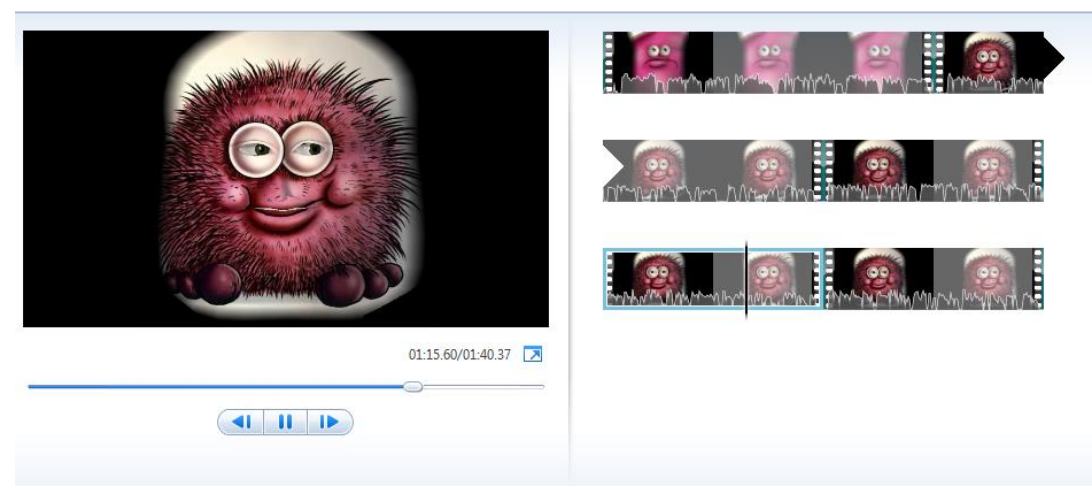

Figure 2: Extract from the Letter and Screenshot of Morfo Video

Events took a final twist when the astronauts discovered that their initial brief - to visit Mercury as an innocent 'fact finding' mission - was misinformation. In actual fact, they were being sent to Mercury as the first stage of a colonising venture.

2 The Morpho app can be used to animate an image and add voiceover

\begin{tabular}{lll}
\hline Language and Literacy & Volume 23, Issue 2, 2021 & Page 8
\end{tabular}




\section{Remembering Professional Commitments}

Despite lots of enthusiasm for this project, from both teachers and children, Jeannie observed that it was difficult to sustain momentum across the schools - real classroom life was forever present. The pressures of workload, curriculum demand and the full range of responsibilities in school had an enduring impact. Despite this, the groups created an ambitious project and the teachers were excited by what the children - and they themselves - achieved. In the end, perhaps, the project had become a sort of hybrid, incorporating some familiar and established classroom activities such as story mapping, collaborative storymaking and speech writing with digital media work such as stop frame animations, blogging, email exchange and Morpho videos.

Reflecting on this project, we might focus on what the children did - the confidence with which they moved across multiple media - both print and digital - and on their motivation to stick with multiple unfolding storylines. We might also draw out how the project provided opportunities for them to engage with the nine principles of the Charter for 21 st Century Literacies, to use, and maybe to expand, their communicative repertoires, to work together across schools, dissolving geographical boundaries (across time and space!). We might also point to the playful, improvisational dimensions, noting perhaps how this enabled children and teachers to go with the flow, and follow directions that emerged as part of the evolving narrative. As such, we could easily map the project against the Charter for $21^{\text {st }}$ Century Literacies. And through doing so of course we might reflect on those principles that were less embedded - the place of criticality ${ }^{3}$, perhaps, and how we might begin to strengthen this dimension in a future project.

However, by mapping the finished project against our principles we omit two significant dimensions of what was going on here. Firstly, we leave out the teachers, and with them their existing interests, commitments and histories of practice. And secondly, we forget the creative, emergent processes through which they sketched out their plans, and the way in which this sort of process often drives forward what happens in classrooms. These dimensions we suggest are key to thinking about how digital media might be better accounted for in schools - and they are captured in Jeannie's observations. Some insights into how this project was conceived and developed hint at why this may be the case.

In June 2016 Jeannie held a two-hour planning meeting with three of the four teachers after school. She clarified that the idea was to plan a collaborative project between them and their classes through which the children would 'build or create' something in a digital space. Jeannie's notes from this meeting give a sense of the discussion that unfolded as teachers made suggestions about what might happen. These are summarised below:

One teacher started by suggesting that each class could make a video for the other classes - something that would teach the audience something. Each school would focus on their topic for the autumn term and make a factual documentary for the other schools. Children would take control of the content of the film to convey their learning to a real audience.

Building perhaps on the idea of collaboration, another suggested that a video could be made collaboratively - one school storyboards it, another school films, another edits, another adds sound-musicleffects, etc. Or they could produce part of a story each.

\footnotetext{
${ }^{3}$ For example, ideas about 'colonising' a place inhabited by 'aliens' could provide rich opportunities for
} critical reflection.

\begin{tabular}{lll}
\hline \hline Language and Literacy & Volume 23, Issue 2, 2021 & Page 9
\end{tabular}


This led to discussion about digital platforms - the children could use digital media to keep in touch, sharing ideas on a blog or using Edmodo as a platform for communication, and the conversation turned at this point to focus on technicalities and procedures linked to $e$ safety, appropriate platforms, the ethics around videoing and parental permissions.

Returning to the idea of collaboration, they focused then on the need to create something with a sense of purpose - a need to create a meaningful context in which children relied on others for feedback. They considered whether this context should be fictional or factual - and whether to open this decision up to the children and ask them. One teacher suggested that perhaps they should start with what they wanted children to gain from the activity and this prompted various ideas- it might provide an opportunity for narration, have a real purpose and audience, or be a factual project through which children could consolidate their learning in other subjects, as well as providing potential for communication.

Combining these ideas, someone else suggested addressing both fact and fictionperhaps focusing on a fictional character that learns about something such as light, or that it might provide an opportunity to learn about different cultures.

The teachers then began to talk about the things they had done in the past year that had inspired the children. They decided that the activities linked to real life events had been the most inspiring, e.g. The trip to the International Space Station by British astronaut Tim Peake, the Queen's birthday, and started googling for events happening the following year. The conversation continued with a rapid fire of suggestions, questions and possibilities: maybe we could have a character that time travels; but who would the audience be? Maybe they could have a premiere their videos in their schools - which might also have fund raising opportunities?

THEN.... one of the teachers, searching on the net, found that NASA had plans to send an unmanned space craft to Mercury. This was the TRIGGER. Suddenly an idea started to form.

- This would be a factual event that would lead to a fictional scenario - what if it was manned?

- How might the experience be presented to others - a newspaper? A blog? Or something else?

- Maybe each class could contribute in a different way - maybe they could take on different roles: NASA, astronauts on the mission, inhabitants of Mercury, people who live on Earth.

- How would we establish the mission and control events?

- Maybe we could present problems along the way that children would have to respond in role - maybe through a blog, or a Big Brother type diary room, perhaps.

- Or maybe they could make a film (stop frame animation, live action or mixed media), maybe including some fake bloopers/behind the scenes footage.

- There could be writing, artwork, documentaries.

As teachers bounced ideas off each other, getting more and more animated with each suggestion, they moved from a very broad brief which could have gone in any direction, to a focused project which inspired them all. Fired up by the idea, the teachers 
decided on the roles their groups would take and went away to think about how the space mission scenario could be introduced and developed.

Jeannie's notes recount how this meeting began with a general pooling of ideas around the task in hand, a laying out of different interests and concerns - possibilities for making videos, for carving up the collaboration, the need for a platform and sense of purpose, learning objectives and motivating events. Here we can trace influences from the wider educational context, such as e-safety policy, and familiar teacher dilemmas about how far to retain control over what children do. These pressing practicalities and imperatives - about resources, security, connectivity and so on - are considered as part of the mix from the very start. Digital media are rarely integrated seamlessly into classrooms and their use often rests on the availability and reliability of equipment and the strength of teachers' logistical planning and relationships with the children they teach. But there are also traces of other, looser commitments - the importance of collaboration and a sense of audience and purpose. And everything starts to fall into place spurred on by an explosion of enthusiasm about imagined events on Mercury. Interestingly, there was very little discussion of the nine principles in the Charter for $21^{\text {st }}$ Century Literacies, and indeed ideas about aims or objectives only surfaced very briefly (linked to reinforcing prior knowledge and developing narrative). However, there was a strong, shared sense of what would 'work' and it is this that we wish to discuss with relevance to thinking about planning for $21^{\text {st }}$ century literacies.

\section{A Remembered Pedagogy}

The work we have described is reminiscent of the project approach that enjoys a long history in English primary schools. Some versions of this approach took place long before computers and wifi entered classrooms. They were open-ended designs that involved imagined adventures such as trips to space (or other times and places) realized not through media but through drama, drawing, writing and making. They had their roots perhaps in Dorothy Heathcote's mantle of the expert (Heathcote and Bolton, 1995), Gordon Wells' story making work (Wells, 1985), or in the use of role play in the early years (Sutton-Smith, 1997). Recent work has picked up and developed this approach by incorporating new media. A uniting theme is that children and their teachers collaboratively create some sort of imagined world. The world provides a context for a wide range of activities and allows children to create complex micro-narratives within it. Examples of this can be found in projects that took place in a virtual world (Merchant, 2009), in a schoolbased Minecraft Club (Bailey, 2016) and through participatory theatre (Burnett et al., 2019). These were all initiatives motivated by a drive to plan contexts for learning that were exciting, responsive and involving, that would provide opportunities for children to drive the direction of their learning, and for meaningful engagement - with ideas, with experience, with text. They were founded on a belief that learning happens through doing, through encountering complex, contradictory situations that prompt children to reflect, engage critically and act meaningfully drawing on the resources to hand.

Of course, these kinds of loosely articulated professional commitments have been the subject of much critique over the last decade or so. They have been undermined and overwhelmed by influential calls for a more evidence-based profession (Goldacre, 2013). Many teachers may well believe that open-ended activities driven by the interests and 
enthusiasm of children are something to aim for, but are they really - and how might we know? Such matters are rather difficult to prove. You can't run a randomized controlled trial on flexibility, unpredictability and fun. And if we can't be sure, the argument seems to go, then maybe we should be directing our attention elsewhere, at things that randomized controlled trials and quasi-experiments suggest might make a difference to test results: things like precise feedback, clear objectives and so on (Hattie, 2008).

Nonetheless our interest here is in the enduring appeal of such approaches not just to children but to teachers too. While such commitments and practices tend to be swept aside during the discussions about performance data that are symptomatic of the accountability culture in England, in our experience they easily slip back in again once teachers get together and start generating ideas about what to do with children in classrooms. Arguably this is what happened during this project, as indeed it has done in many similar projects in which we've been engaged. And it is this, we suggest, that makes it possible to begin to address more contemporary literacy practices in classrooms.

Such approaches push back against the atomization of accountability education and they are certainly a far cry from objectives-driven lesson planning. We might read into the teachers' planning discussion an implicit belief that if children's imagination can be caught and the class can be carried away by a shared endeavour, then everything else will follow. The promise of the project seems to rest on both togetherness and escape: the successful creation of classroom community produced in classes of children and teachers that work and play together over time within four walls (Burnett, 2015), and some boundary-breaking communication planned across real and imagined spaces. However, this account also complements the production of rubrics and frameworks to address 'the digital' (e.g. Redecker \& Punie, 2017). The imperative for collaboration, criticality and meaningful communication may well have been amplified in a digital age, but they are certainly not new. Indeed, if we extracted the words 'media' and digital' from our Charter for $21^{\text {st }}$ Century Literacies, these principles might well feel very familiar to teachers teaching fifty years ago.

\section{Re-Opening - A Conclusion}

Classrooms and schools are important places. We certainly didn't need a pandemic to teach us that, but if we were in any doubt, the opportunities that some children and some parents have missed out on from school closure have been cast into sharp relief by Covid19. For all the possibilities of virtual learning and all the ideological support for home education, school closure has been seen to compound disadvantage and social isolation to magnify marginalization. At the same time, pandemic conditions have prompted some new ways of working. Many teachers for example have drawn on digital media in their attempts to make home learning accessible and enjoyable, linking to stories or film clips on YouTube to be shared prior to an online lesson, for example, and encouraging children to talk about these with family members if they can. Others have explored ways of using digital platforms to help sustain a sense of community while children are physically separated - posting ideas and opinions on Padlet for example so they can be shared amongst the group. This kind of work reflects not only the nine principles of the Charter for $21^{\text {st }}$ Century Literacies but more longstanding commitments to collaboration and authentic texts. The pandemic has also encouraged teachers to find new ways to collaborate together 
as professionals, forming digital 'maker circles' with colleagues via Twitter chats and virtual conferences, allowing them to meet with like-minded teachers who may or may not have comparable histories of practice but nevertheless have similar commitments. Even after Covid it is likely that some of these digital collaborative professional spaces will continue to thrive. Working closely with teachers and listening carefully to them will be important in rebuilding confidence and cohesion. After all they are the experts in doing that.

\section{References}

Bailey, C. (2016). Free the sheep: Improvised song and performance in and around a Minecraft community. Literacy, 50(2), 62-71.

Burnett, C. (2015). Being together in classrooms at the interface of the physical and virtual: implications for collaboration in on/off screen sites. Learning, Media and Technology, 41(4), 566-589.

Burnett, C., Davies, J., Merchant, G. \& Rowsell, J. (Eds.) (2014). New literacies around the globe: Policy and pedagogy. Routledge.

Burnett, C. \& Merchant, G. (2015). The challenge of $21^{\text {st }}$ century literacies. Journal of Adult and Adolescent Literacies, 59(3), 271-274.

Burnett, C. \& Merchant, G. (2018). New media in the classroom: Rethinking primary literacy. Sage.

Burnett, C., Parry, B., Merchant, G., \& Storey, V. (2020). Treading softly in the enchanted forest: Exploring the integration of iPads in a participatory theatre education programme. Pedagogies: An International Journal, 15(3), 203-220.

Cope, B., \& Kalantzis, M. (Eds.). (2000). Multiliteracies: Literacy learning and the design of social futures. Routledge.

Goldacre, B. (2013). Building evidence into education. Department for Education. https://www.gov.uk/government/uploads/system/uploads/attachment_data/file/19 3913/Building_evidence_into_education.pdf

Hattie, J. (2009). Visible learning: A synthesis of 800+ meta-analyses on achievement. Routledge.

Heathcote, D., \& Bolton, G. (1995). Drama for learning: Dorothy Heathcote's mantle of the expert approach to education. Heinemann.

Jenkins, H., Purushotma, R., Weigel, M., Clinton, K., \& Robison, A. J. (2009). Confronting the challenges of participatory culture: Media education for the 21 st century. Massachusetts Institute of Technology.

Kontovourki, S., \& Tafa, E., (Eds.). (2019). Early years' and primary teachers' digital literacies in personal lives and professional practice: A cross-country report. DigiLitEY: WG2 Digital Literacy in Early Years Settings, Schools, and Informal Learning Spaces. http://digilitey.eu/wp-content/uploads/2020/07/WG2Report.pdf

Merchant, G. (2009). Literacy in virtual worlds. Journal of Research in Reading, 32(1), $38-56$.

Monkhouse, J., Bailey, C., Baker, W., Power, D., Bailey, C. Burnett, C., Daniels, K., Merchant, G. (2017). Word on the street. English 4-11. Spring 2017(59), 17-20. 
Moss, G., Allen, R., Bradbury, A., Duncan, S.,Harmey,S., Levy, R. (2020). Primary teachers' experience of the COVID-19 lockdown - Eight key messages for policymakers going forward. University College London. https://discovery.ucl.ac.uk/id/eprint/10103669/1/Moss_DCDT\%20Report\%201\% 20Final.pdf

National Literacy Trust. (2017). Fake news and critical literacy. https://cdn.literacytrust.org.uk/media/documents/Fake_news_and_critical_literacy -_final_report.pdf

Redecker, C., \& Punie, Y. (Ed.) (2017) European framework for the digital competence of educators: DigCompEdu. EUR 28775 EN. Publications Office of the European Union, Luxembourg. https://ec.europa.eu/jrc/en/publication/eurscientific-and-technical-research-reports/european-framework-digitalcompetence-educators-digcompedu

Sutton-Smith, B. (1997). The ambiguity of play. Harvard University Press.

\section{Author Biographies}

Jeannie Bulman earned her Ph.D. from the University of Sheffield (UK) and specializes in all aspects of primary English teaching and learning. Her 2015 doctoral research won the UK Literacy Association's award for research in 2016 and her monograph, 'Children's Reading of Film and Visual Literacy in the Primary Curriculum: A Progression Framework Model' (Palgrave Macmillan, 2017) was nominated for UKLA's Academic Book Award 2018. She has also co-authored 'Film Education, Literacy and Learning' with Becky Parry (UKLA 2017) and the chapter Children's Literature on Screen with Lucy Taylor in 'The Palgrave Handbook of Children's Film and Television' (2019).

Cathy Burnett is Professor of Literacy and Education at Sheffield Institute of Education, Sheffield Hallam University where she leads the Language and Literacy in Education Research Group. Her books include 'Undoing the Digital' (2020), 'New Media in the Classroom' (2019) (both with Guy Merchant) and the co-edited collections: New Literacies around the Globe' (2014); 'Literacy, Media, Technology' (2016) and 'The Case of the iPad' (2016). She is a Past President of the United Kingdom Literacy Association.

Guy Merchant is Professor of Literacy and Education at the Sheffield Institute of Education, Sheffield Hallam University. His research explores the ways in which literacy and technology intersect in the lives of children and young people. Guy is a founding editor of the Journal of Early Childhood Literacy and has written extensively about literacy and new media. He is co-author, with Cathy Burnett, of 'Undoing the Digital' (2020), 'New Media in the Classroom' (2019), and is a contributing editor for 'Virtual Literacies' (2013); 'New Literacies around the Globe' (2014); 'Literacy, Media, Technology' (2016) and 'The Case of the iPad' (2016). 
Emma Rogers is a Senior Lecturer at Bishop Grosseteste University teaching English in Education. She worked for several years for the Primary National Strategies leading the successful Every Child a Writer programme and has developed languages curricula and assessment guidance in over 150 countries. She is currently studying for her $\mathrm{PhD}$, researching student teacher's reading identities. 